\title{
CARANGA Y EL MANEJO SIMBÓLICO DE LA VERTIENTE OCCIDENTAL ANDINA (PRECORDILLERA DE ARICA)*
}

\author{
THE CARANGA AND THE SYMBOLIC MANAGEMENT OF THE WESTERN \\ ANDEAN WATERSHED (PRECORDILLERA OF ARICA)
}

\author{
Juan Chacama Rodríguez,**
}

\begin{abstract}
Se propone que durante la prehistoria tardía de la precordillera de Arica o Altos de Arica se llevó a cabo en dicha zona una interacción cultural, política y económica entre poblaciones de tradición de valles occidentales y poblaciones altiplánicas, específicamente Caranga. Paralelamente a las mencionadas formas de interacción, la etnia Caranga habría sostenido además un manejo simbólico del espacio cordillerano, al que hoy podemos acceder mediante ciertos tipos de representaciones que han dejado sus huellas en el imaginario de estas poblaciones así como en el paisaje cultural dejado por ellas. Dichas representaciones hacen referencia a la invocación de los cerros y a la construcción de estructuras arquitectónicas vinculadas al ámbito ritual, que en su conjunto nos aproximan a la ideología Caranga y por ende al manejo simbólico de la vertiente occidental andina.
\end{abstract}

Palabras claves: Manejo simbólico, Caranga, precordillera de Arica.

It is proposed that during the late prehistory of the precordillera of Arica or 'Altos de Arica', there were cultural, political and economic interactions between populations of the western valleys and the highland populations, specifically the Caranga. Parallel to the above forms of interaction, the ethnic Caranga have also held the mountain as a symbolic space, which today can be understood through certain types of representations that have left their mark in the minds of these populations as well as in the cultural landscape. These representations make reference to the invocation of the hills and the construction of architectural structures linked to the ritual sphere, which when together allow us to approximate the Caranga ideology and therefore the symbolic management of the Andean western watershed.

Key Words: Symbolic Management, Caranga, Precordillera of Arica.

\section{Introducción}

La documentación colonial ha entregado evidencias que la población que habitaba la precordillera de los Altos de Arica durante los primeros siglos de la Colonia dependía cultural y administrativamente de la etnia altiplánica de los Caranga; así, diversos señores principales asentados en las cabeceras de los valles occidentales dependían del gran señor Chuquichambe, principal de la etnia Caranga. Por otra parte y a partir de la misma documentación se ha propuesto que las relaciones político-administrativas entre ambos pisos ecológicos se remontarían a épocas prehispánicas.

Las investigaciones arqueológicas, por su parte, señalan que la precordillera de los Altos de Arica habría sido ocupada a partir del primer milenio d.C. por poblaciones propias de los valles bajos de la vertiente occidental, las que posteriormente habrían interactuado con poblaciones altiplánicas, Caranga; estas últimas habrían accedido a la vertiente occidental en busca de tierras con alternativas de producción agrícola y que con el paso de los siglos habrían impuesto una hegemonía política sobre las primeras.

En dicho contexto se intenta mostrar que paralelamente a los procesos políticos y económicos llevados a cabo por las poblaciones Caranga en su proceso de hegemonización del territorio precordillerano, estas tuvieron un manejo simbólico de dicho espacio. Para ejemplificar nuestra propuesta se recurre al análisis de tres sistemas de representación simbólica llevados a cabo por dichas poblaciones.

El primero de ellos evidencia sistemas que permanecen en la memoria de algunos enclaves Caranga de la actualidad como lo es el "rodamiento grande" entre los Sabayas, cuyos componentes nos remiten a un territorio que se extiende más allá de la actual comunidad de Sabaya y nos sugiere un espacio mayor, quizás prehispano, que incluye a la actual precordillera de los Altos de Arica.

* Resultado del Proyecto FONDECYT N ${ }^{\circ}$ 1100132. Agradecimientos al Convenio de Desempeño UTA-MINEDUC.
** Universidad de Tarapacá, Departamento de Antropología, Arica, Chile. Correo electrónico: jchacama@ uta.cl 
La segunda representación son los edificios funerarios conocidos como chullpas, que se encuentran a lo largo de toda la precordillera y cuya función podría señalarse como poliicónica en el sentido de que tras dichos edificios encontramos múltiples significaciones que van desde el culto a los ancestros a marcadores territoriales, por mencionar algunas.

Una tercera representación, considerada aún como una propuesta, hace referencia a un tipo particular de arquitectura que se encuentra presente en el conjunto arquitectónico asociado al mito del "Tata Sabaya" en el altiplano sur de Bolivia, así como en uno de los poblados prehispánicos de la precordillera ariqueña: Incaullo.

Con las tres representaciones arriba mencionadas se intentará entonces realizar una aproximación al manejo simbólico de la precordillera de Arica por parte de la población Caranga.

\section{El contexto}

La precordillera de Arica, conocida también como Altos de Arica, es parte constituyente de la cordillera de los Andes; para esta investigación los Altos de Arica se remiten al tramo precordillerano correspondiente a las cabeceras de la cuenca hidrográfica del río San José (valle de Azapa), la que se encuentra limitada por el norte por el río Seco o quebrada de Zapahuira y por el sur por las nacientes del río Ticnamar a los pies del cerro Marqués. Con cotas oscilantes entre los 3.000 y $3.500 \mathrm{msnm}$ (Figura 1). Su cubierta vegetacional está constituida en gran medida por distintas especies de tolas (parastrefias sp.), y una gran variedad de cactáceas. Orográficamente este sector de la cordillera de los Andes está constituido por un conjunto de pequeños valles cuyas nacientes se encuentran en vertientes precordilleranas y sus aguas son recogidas por el mencionado río Ticnamar, el que fluye por una falla geológica en dirección sur-norte que al juntarse con el río Seco, cuyo afluente viene en dirección norte-sur, ambos tuercen hacia el oeste dando inicio al valle de Azapa.

Los pequeños valles precordilleranos arriba reseñados se inician de norte a sur con el mencionado río Seco, seguido por los ríos Laco, Chapiquiña, Pachama, Belén, Lupica, Saxamar, Ticnamar, entre los más importantes. Estos, como señalábamos, tienen sus nacientes en la vertiente occidental de la cordillera de los Andes donde son más abiertos, los que a medida que fluyen hacia el oeste se van encajonando y sus laderas se tornan más abruptas hasta convertirse en estrechas gargantas al momento de drenar sus aguas en el río Ticnamar (Figura 1).

Desde tiempos preinca y hasta nuestros días los mencionados valles constituyen el eje de los asentamientos humanos en la zona; en sus cabeceras y a lo largo de sus laderas se fueron constituyendo diversos poblados cuya principal fuente energética y económica fue y es la agricultura practicada en sistemas de terrazas agrícolas e irrigadas por complejos sistemas de canales de regadío.

La investigación etnohistórica realizada para el extremo norte de Chile da cuenta de una temprana multietnicidad presente en la costa y valles de Arica con sus respectivas cabeceras, situación que tendría su origen en tiempos prehispanos (Hidalgo, 1996, 1997; Hidalgo y Focacci, 1986; Hidalgo et al., 1991, entre otros). En dicho mapa multiétnico, en tiempos prehispanos, en la sierra de Arica destaca la presencia de poblaciones yungas, conocidas también como Cultura Arica y la etnia Caranga; esta última constituye "el vecino" más cercano de las poblaciones yungas de los valles ariqueños, de hecho, la documentación colonial la menciona constantemente como presente en las cabeceras de estos valles y a lo largo de ellos.

$\mathrm{Al}$ respecto G. Riviere señala que

se sabe que en los tiempos anteriores a
la conquista y aún hasta el siglo XVII, la
provincia de los karankas sobrepasaba
ampliamente sobre el actual territorio
chileno y abarcaba pueblos que tenían
la misma organización política que los
de la altura. Entre estos se puede citar
los de Codpa, Pachica, Timar, Tignamar,
Esquiña, Pujyo, etc. Algunos de los cuales
están ubicados en valles o caberas de valle.
Riviere (1979:4, 1982).

Por su parte, A. Durston y J. Hidalgo, haciendo uso de textos de reclamos y cédulas de encomienda, señalan que "Los antecedentes documentales que poseemos sobre el establecimiento y la organización de la presencia altiplánica en los valles de Arica son fragmentarios, pero permiten vislumbrar un grado de hegemonía por parte de los Caranga". Durston e Hidalgo (1999:252).

Desde otro punto de vista, una aproximación a la forma de acceso a las tierras de los valles del Pacífico y la organización social y política que 


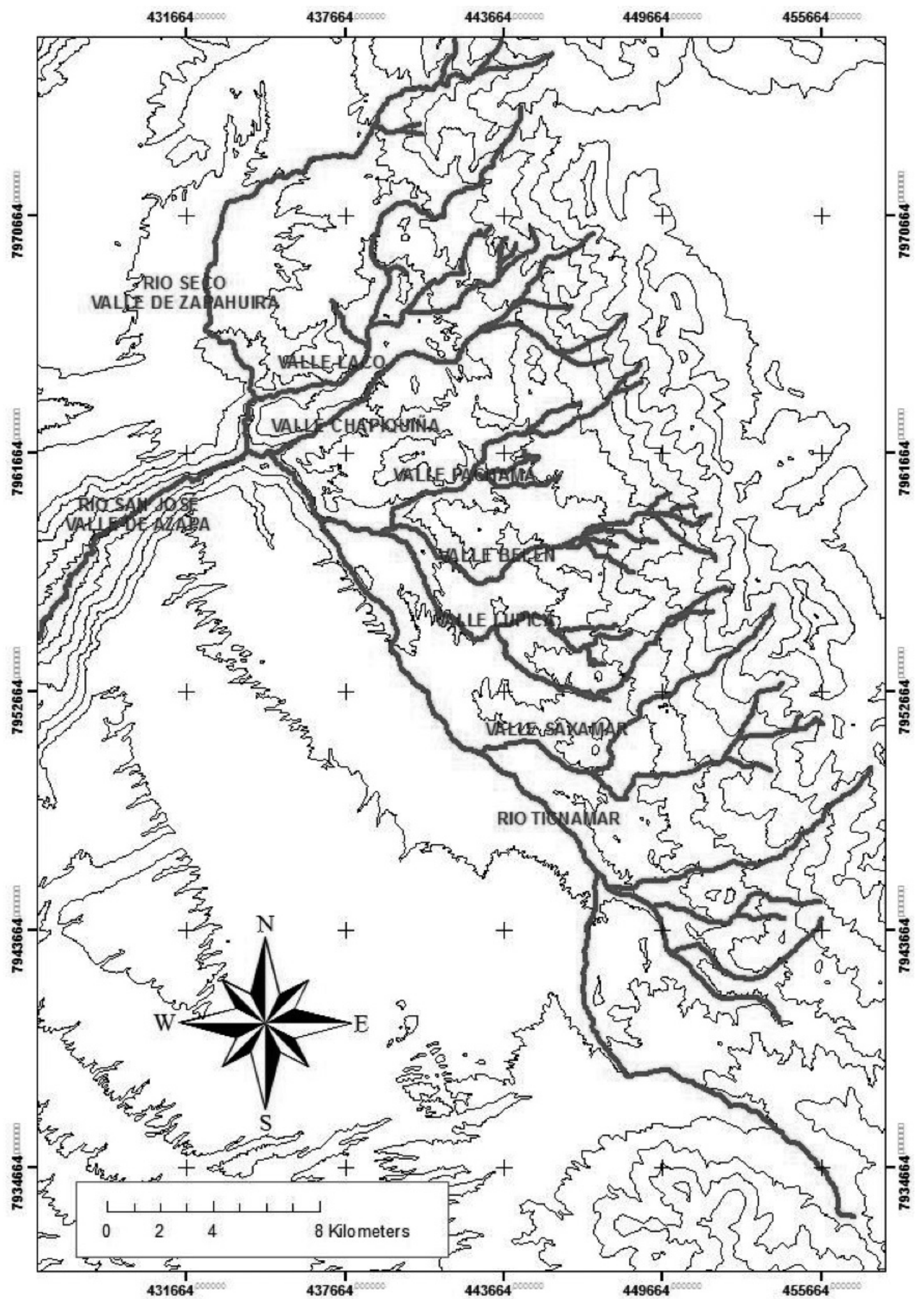

Figura 1. Cabecera cuenca hidrográfica río San José (valles precordilleranos). 
les permitiría a los Caranga mantener enclaves en estos valles, puede visualizarse mediante la aproximación que T. Platt hace de los qharaqhara, confederación aymara ubicada inmediatamente al sur de la etnia Caranga. Siguiendo a Murra, Platt propone el manejo de una franja transcordillerana por parte de los distintos grupos étnicos altiplánicos, la que involucraría territorios en ambas vertientes cordilleranas, incluyendo la franja altiplánica. La organización social y política de esta franja se reflejaría en un sistema segmentario dual que atraviesa toda la organización desde su nivel mayor hasta las unidades más pequeñas: pacas, dirigido este por señores principales en diferentes niveles de jerarquías que tienen la característica de estar presentes en cada espacio territorial en que la etnia se encuentre (Platt, 1988) ${ }^{1}$.

Para nuestra zona de interés, Arica, sus valles y cabeceras, Durton e Hidalgo acotan dicho planteamiento proponiendo para la etnia Caranga un modelo de verticalidad escalonada, el que opera en tres niveles: centros primarios, secundarios y terciarios. El modelo implica el desdoblamiento de todas las estructuras verticales: la relación entre centro primario y secundario es la misma que entre centro secundario y terciario. Las colonias son ellas mismas generadoras de verticalidad, estableciéndose como centros en relación con otras colonias (Durton e Hidalgo, 1999:255). Los centros primarios corresponderían a los grandes centros altiplánicos, donde los autores mencionan el gran centro altiplánico de Turco: Hatun Caranga; los centros de segundo orden corresponden a los enclaves precordilleranos y los de tercer orden a aquellos asentamientos menores distribuidos en los valles bajos y en la zona costera (Durton e Hidalgo, 1999).

\section{Rodamiento Grande. Primera representación}

Un aspecto característico de las poblaciones andinas, actuales y pasadas, es el venerar a sus divinidades tutelares, dentro de las cuales los cerros ocupan un nivel relevante, especialmente las cumbres nevadas.

\footnotetext{
"Los cerros nevados están relacionados con la producción del agua para los cultivos, pertenecen a la categoría de los apukuna, espíritus de jerarquía superior y recibían a menudo ofrendas de seres humanos" (Polia 1999:167).
}

En el contexto señalado mencionamos el llamado a los cerros tutelares que se practica hasta nuestros días en la región de Sabaya, territorio Caranga ${ }^{2}$. En determinadas celebraciones, la comunidad de Sabaya, conducida por sus alféreces, realiza una serie de invocaciones las que denominan como rodamiento grande, rodamiento chico y ch'alla a la marka. El rodamiento grande implica la mención e invocación a un conjunto de cerros que se encuentran a $100 \mathrm{~km}^{3}$ y más de la localidad de Sabaya, este rodamiento involucra cumbres tan lejanas como el Illampu, a 350 $\mathrm{km}$ de distancia; por su parte, el rodamiento chico implica cerros cercanos, visibles desde la localidad y, finalmente, la ch'alla a marka ${ }^{4}$ involucra diversas estructuras existentes en el pueblo de Sabaya como la iglesia, su torre, la plaza, etcétera.

En relación con nuestro tema de estudio, nos interesa centrarnos en lo que se denomina rodamiento grande (jach'a), aquel que hace referencia a un conjunto de cerros distantes de la localidad de Sabaya, que no se ven a simple vista y cuyo conocimiento se encuentra en la memoria de sus habitantes. Las cumbres mencionadas en este rodamiento son ${ }^{5}$ : Mallku Sillajualla, Tunupa, Coracorani, Asanaque, Tunari, Illimani, Illampu, Doctor Sajama, Kimsachata, Chungara ${ }^{6}$, Guallatire, Márquez, Mamuta, Tolompa, Jachura, Unita, Huantajalla, Dragón. Tungapan angela 7 (figura 2).

A nuestro entender, el conjunto de cerros mencionados en el rodamiento grande hacen referencia a un espacio ancestral guardado en la memoria de los habitantes de Sabaya ${ }^{8} \mathrm{y}$, sin pretender explicar dicho espacio, nos parece interesante observar algunos temas. En términos generales, la invocación de los hitos mencionados siguen el sentido inverso a las manecillas del reloj ${ }^{9}$, partiendo desde el cerro Sillajuaya en la misma localidad de Sabaya, siguiendo por cerros ubicados en Bolivia, y terminando con una serie que se encuentra en el actual territorio chileno: Chungara, Guallatire, Márquez, Mamuta, Tolompa, Jachura, Unita, Huantajalla y Dragón.

Los primeros dos cerros de la serie ubicada en territorio chileno: Chungara y Guallatire, se encuentran en el altiplano en el borde mismo de la actual frontera chileno-boliviana; Marquéz, Mamuta, Tolompa, Jachura están ubicados en plena cordillera de Los Andes (Altos de Arica); Unita es una duna (cerro isla) que se encuentra a la altura del pueblo de San Lorenzo de Tarapacá en la pampa del Tamarugal y finalmente, Huantajalla 


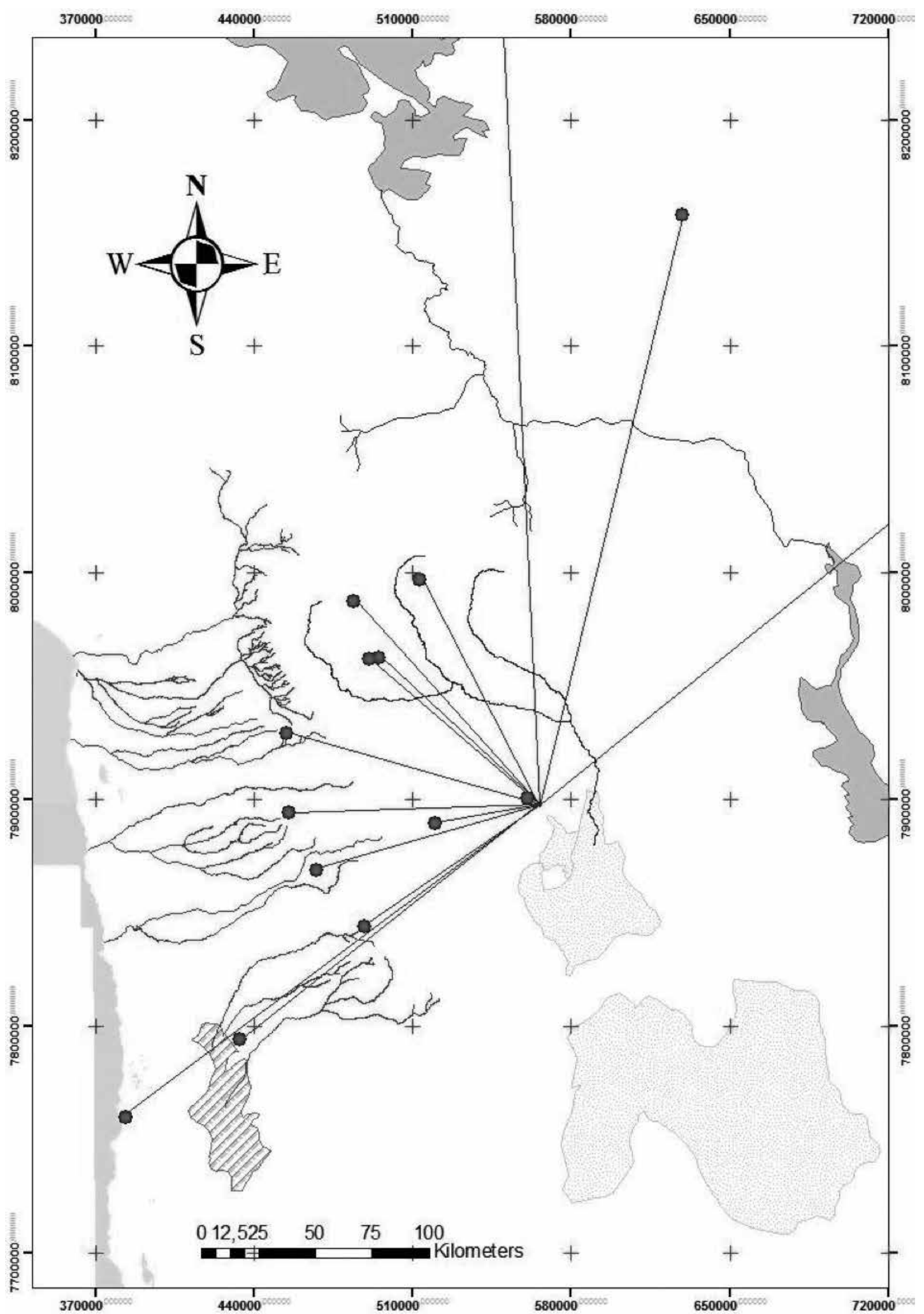

Figura 2. Hitos geográficos Rodamiento Grande, Sabaya. 
y Dragón están en la bajada al puerto de Iquique; este último, una duna de gran tamaño, se encuentra en plena ciudad casi rodeada completamente por el crecimiento urbano.

Nos interesa ahora centrarnos en aquellos hitos ubicados en la precordillera de los Altos de Arica; estos se encuentran en las cabeceras de los valles occidentales y en cierta medida son coincidentes con la ubicación de los poblados que Riviere señala como correspondientes a la provincia Caranga: Codpa, Pachica, Timar, Tignamar, Esquiña, Pujyo, etc. Algunos de los cuales están ubicados en valles o caberas de valle (Riviere, 1979:4, 1982). De igual modo, en la misma franja precordillerana se encuentran ubicados un conjunto de sitios arqueológicos que datan de la época pre-Inca e Inca (períodos Intermedio Tardío y Tardío, respectivamente); en dichos poblados se han encontrado tres componentes cerámicos: estilos Inca, estilos de valles occidentales y estilos altiplánicos, estos últimos de filiación Caranga (Muñoz y Chacama, 2006). Reforzando la presencia de estilos cerámicos prehispánicos, vinculados a Caranga, en dichos poblados se encuentra la presencia de sepulcros del tipo Chullpas, de evidente tradición altiplánica, algunos de ellos presentan una tecnología similar a las Chullpas presentes en territorio Caranga (Chacama, 2009).

Como ya señaláramos, el rodamiento mayor al nombrar los cerros de la precordillera de Arica, hace referencia a un territorio ancestral que se encuentra presente en la memoria colectiva de los actuales habitantes de Sabaya, y si bien estos no recuerdan explícitamente las relaciones políticas, culturales y/o económicas que pudieron haber tenido con dicho espacio, sabemos sí que, al menos en lo que respecta a la zona de los Altos de Arica, este espacio estuvo vinculado política y culturalmente a la etnia Caranga y así lo demuestran los registros arqueológicos y la documentación colonial. Por tanto, cuando se invoca el rodamiento grande también se está invocando de manera simbólica dicho territorio $\mathrm{y}$, con él, las relaciones existentes entre Caranga y la precordillera de los Altos de Arica.

\section{Sepulcros abiertos, Chullpas. Segunda representación}

En su trabajo Mortuoty Practice... W. Isbell señala que en tiempos coloniales la estructura social conocida como Ayllu se caracteriza por un conjunto de factores, dentro de ellos destaca el contar con un ancestro común, origen del Ayllu, con el que se brinda y se comparte en ceremonias públicas, lo que hace necesario que sus sepulcros posean un vano de acceso que facilite la interacción entre los muertos y los vivos. Dicho factor, el del ancestro común, podría testearse en épocas precoloniales (prehispanas) por medio de aquellas sepulturas que poseen un vano de acceso directo a los cuerpos en ellos depositados (Isbell, 1996) (Figura 3) y cuyo contexto ha sido caratulado como culto a los ancestros (cif. Doyle, 1989; Salomón, 1995). Dichos sepulcros en la zona del altiplano meridional y su correspondiente sección precordillerana han sido denominados bajo el nombre de Chullpas. Estas estructuras arquitectónicas si bien tienen como función principal contener los cuerpos de difuntos, su función es más bien polisemántica, en el sentido de tener múltiples significados, como ha sido propuesto tanto por la documentación colonial como por las investigaciones arqueológicas.

\section{La voz de las crónicas}

No es la intención de este acápite realizar un estudio acucioso de los documentos coloniales que hacen alusión a las Chullpas, sino más bien exponer una visión sucinta de lo que tempranos funcionarios de la Corona y algunos religiosos percibieron de estos monumentos; del mismo modo, se extrae de dicha documentación una categorización del rol de las Chullpas.

\section{Entierro, estatus y sacrificios}

La mayoría de las fuentes documentales tempranas señalan que los edificios conocidos como Chullpas estuvieron destinados a enterratorios, particularmente de cierta gente de importancia social, y en cuyos alrededores se llevaron a cabo diversos sacrificios de culto en torno a los actos de la muerte. (i.e. Cieza de León, 1986 [1553]:275, 285; Ramos Gavilán, 1976 [1621]: 73; Mercado de Peñalosa, 1965 [1583]:339; Virrey Francisco de Toledo, en Gisbert, 1988:122; Diego Quispe [1612] en Platt, 1988: 385).

\section{Marcadores de frontera}

No obstante lo anterior, algunas fuentes coloniales señalan también que estos edificios 


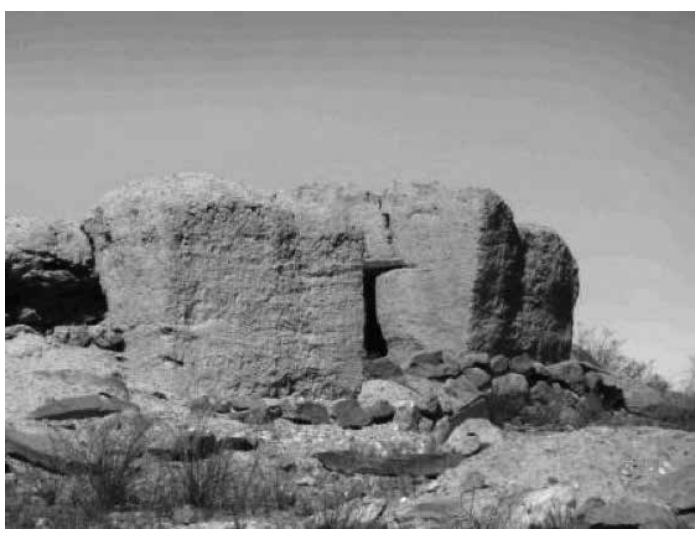

Foto 1. Chullpa de barro, sitio Caillama.

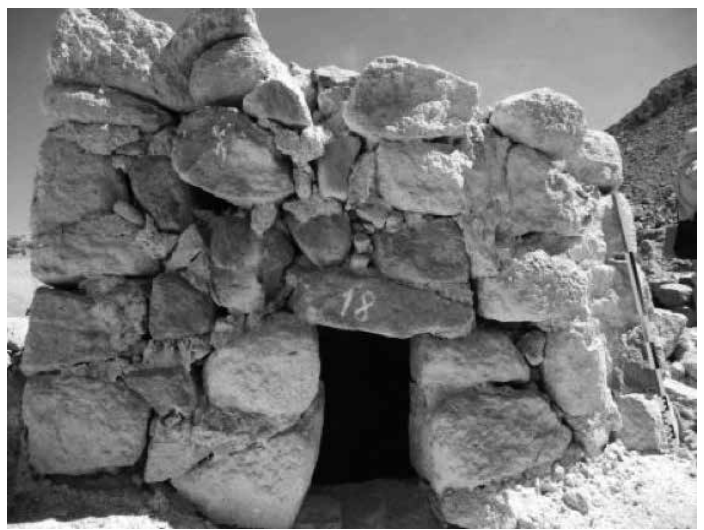

Foto 2. Chullpa de piedra enlucida con barro, sitio Copaquilla.

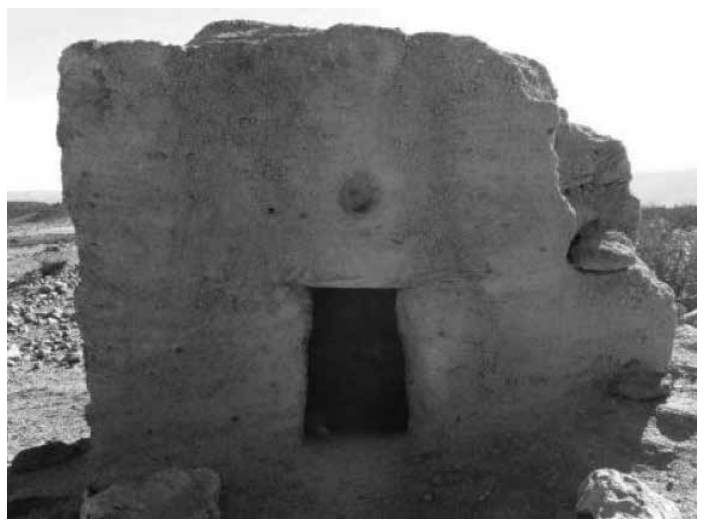

Foto 3. Chullpa aislada de adobe, sector Zapahuira.

Figura 3. Chullpas en la precordillera de Arica.

pudieron haber servido como marcadores territoriales o de fronteras. Bernabé Cobo, en el siglo XVII, señala que las Chullpas que él observó en la provincia de Caracollo fueron emplazadas en la propiedad de la familia del difunto (Cobo, 1964[1562]:273). Por su parte, en los Archivos de Indias, de 1564 (Hyslop, 1977: 151), se señala que el texto describe la mensura de la tierra que podría servir a la iglesia del pueblo de Chucuito, en la que el rey Lupaca supervisa personalmente la demarcación de la tierra usando Chullpas como marcador de frontera.

En otros documentos, Garci Diez de San Miguel (1964[1567]) y Pedro Gutiérrez Flores (1964 [1574]) (en Hyslop, 1977:152) entregan una lista de nombres de indios ricos o líderes de la región Lupaca. Abriendo la posibilidad que las Chullpas existentes en esa región pudieran ser encontradas en las tierras de dichos señores, lo que permitiría definir un patrón de tierras controlados por elites familiares con presencia de Chullpas.

Por último, Guaman Poma de Ayala (1944[1615]:f.352,355) presenta una lámina que ilustra un mojón de frontera con aspecto similar a una Chullpa circular con cornisas moldeadas. Chullpas de este estilo son ubicadas en el territorio Lupaca.

\section{Las investigaciones arqueológicas}

No son pocos los investigadores y las investigaciones llevadas a cabo por la Arqueología en torno al tema de las Chullpas. Aldunate y colaboradores (1982) entregan un detallado panorama de las investigaciones, realizadas hasta esa fecha; los autores, respecto de la función de las Chullpas, señalan que:

\section{En suma, la revisión de la literatura andina sobre las chullpas ofrece básicamente cinco hipótesis sobre la funcionalidad de estas estructuras, tres de ellas "seculares" (habitación, silo y marcador territorial) y dos "ceremoniales" (cámara funeraria y lugar de ofrendas) (Aldunate et al., 1982:135) ${ }^{10}$.}

A las dos grandes categorías de secular y ceremonial señalada por Aldunate y colaboradores, agregamos una categoría político-social, la que se hace evidente en el destino de las Chullpas como cámaras funerarias para la elite de la comunidad que las erigió (Chacama, 2009a; Duchessne y Chacama, 2012). Esta función político-social se sustenta también en la propuesta de que estos monumentos constituyen indicadores simbólicos de la presencia ideológica y política de las etnias Aymara en determinadas regiones (cif Castro et al., 1984; Romero, 
2002). Otro aspecto de esta categoría tiene que ver directamente con las chullpas como indicadores de organización social (Isbell, 1996).

Con los antecedentes en mano intentaremos una lectura de síntesis de algunas de las funciones propuestas a los edificios chullpas. Estas hacen referencia a sepulcros destinados a la elite, señores principales cuyo poder habría seguido actuando aun luego de su muerte, situación que habría sido manifiesta en periódicas celebraciones a sus cuerpos momificados; estos fueron sacados de sus sepulcros y en espacios públicos alternaron con la comunidad viva, "brindando" los unos con los otros.

Por otra parte, los sepulcros -chullpas- simbolizan la presencia de las etnias altiplánicas en el espacio precordillerano, demandando una tuición sobre dicho espacio mediante una tenencia ancestral de la tierra. En otras palabras, los sepulcros de elite erigidos por las poblaciones altiplánicas están orientados a señalar que el espacio precordillerano fue poblado por sus ancestros y a ellos pertenece la tierra y sus beneficios ${ }^{11}$. Los sepulcros chullpas son en este sentido un manejo simbólico de la presencia altiplánica y del dominio ancestral del espacio precordillerano (Figura 4).

\section{Un singular edificio. Tercera representación}

Señalábamos en la presentación de este trabajo que esta tercera representación más que un tema avanzado debe ser considerado como una propuesta de trabajo. Señalado lo anterior, examinaremos las estructuras que nos permiten desarrollar la propuesta.

\section{Incaullo (corral del inca)}

En el valle de Belén, precordillera de Arica, existe un conjunto de asentamientos humanos prehispánicos pertenecientes a la época tardía de la prehistoria regional (ca. 1100 - 1550 d.C.); estos se encuentran a la vera del río Belén en un nivel de cotas que oscila entre 3.000 y $3.200 \mathrm{msnm}$ (lámina 3). Dichos asentamientos se encuentran insertos en amplios terrenos agrícolas utilizados, desde épocas prehispánicas hasta nuestros días, bajo una modalidad de terrazas (andenes) de cultivos irrigados por una vasta red de canales de regadío (Figura 5).

En lo que concierne a nuestra propuesta, resulta de interés el sitio Incaullo, investigado inicilamente por P. Dauelsberg en la década de los años 60 y publicado en 1983. Aunque su función aún no está completamente definida, Incaullo se compone de varias edificaciones poco comunes en la zona, como lo son cuatro chullpas de piedra cuyos vanos, a diferencia de otros edificios similares, están orientados al oeste (una de ellas presentaba un enlucido de barro y pintura roja (Dauelsberg, 1983:73)); dos plantas rectangulares de tamaño regular que podrían corresponder a Kallancas; edificios rectangulares sin vano de acceso, que según Dauelsberg (1983:73) podrían corresponder a depósitos (collcas) y otros edificios, actualmente muy derruidos para intentar determinar su función. Dentro del conjunto de edificaciones de Incaullo, destaca un recinto circular, utilizado actualmente como corral, función que, por la cantidad de estiércol en su interior, debe haberla cumplido por muchos años. A nuestro juicio, es

Tabla 1. Asentamientos humanos prehispánicos en el valle de Belén

\begin{tabular}{|c|c|c|c|}
\hline Asentamiento & Característica & $\begin{array}{l}\text { Asociación } \\
\text { cronocultural }\end{array}$ & Referencia \\
\hline Ancopachane & Aldea & Culturas regionales & $\begin{array}{l}\text { Daueslberg, } 1983 \\
\text { Muñoz y Chacama, } 2006\end{array}$ \\
\hline Chajpa & $\begin{array}{l}\text { Instalación } \\
\text { Inca }\end{array}$ & Presencia Inca & $\begin{array}{l}\text { Daueslberg } 1983 \\
\text { Muñoz y Chacama, } 2006\end{array}$ \\
\hline Aldea (Belén)* & Aldea & ¿Culturas regionales? & No investigado \\
\hline Incaullo & $\begin{array}{l}\text { Instalación } \\
\text { Inca }\end{array}$ & Presencia Inca & $\begin{array}{l}\text { Daueslberg, } 1983 \\
\text { Muñoz y Chacama, } 2006\end{array}$ \\
\hline Huaihuarani & Aldea Pukara & Culturas regionales & $\begin{array}{l}\text { Daueslberg, } 1983 \\
\text { Muñoz y Chacama, } 2006 \\
\text { Romero, } 2005\end{array}$ \\
\hline Caragua & Ceremonial & ¿? & No investigado \\
\hline
\end{tabular}

*El sitio no tiene nombre designado, se le otorga el nombre tentativa de aldea Belén por encontrarse junto al poblado actual de mismo nombre. 


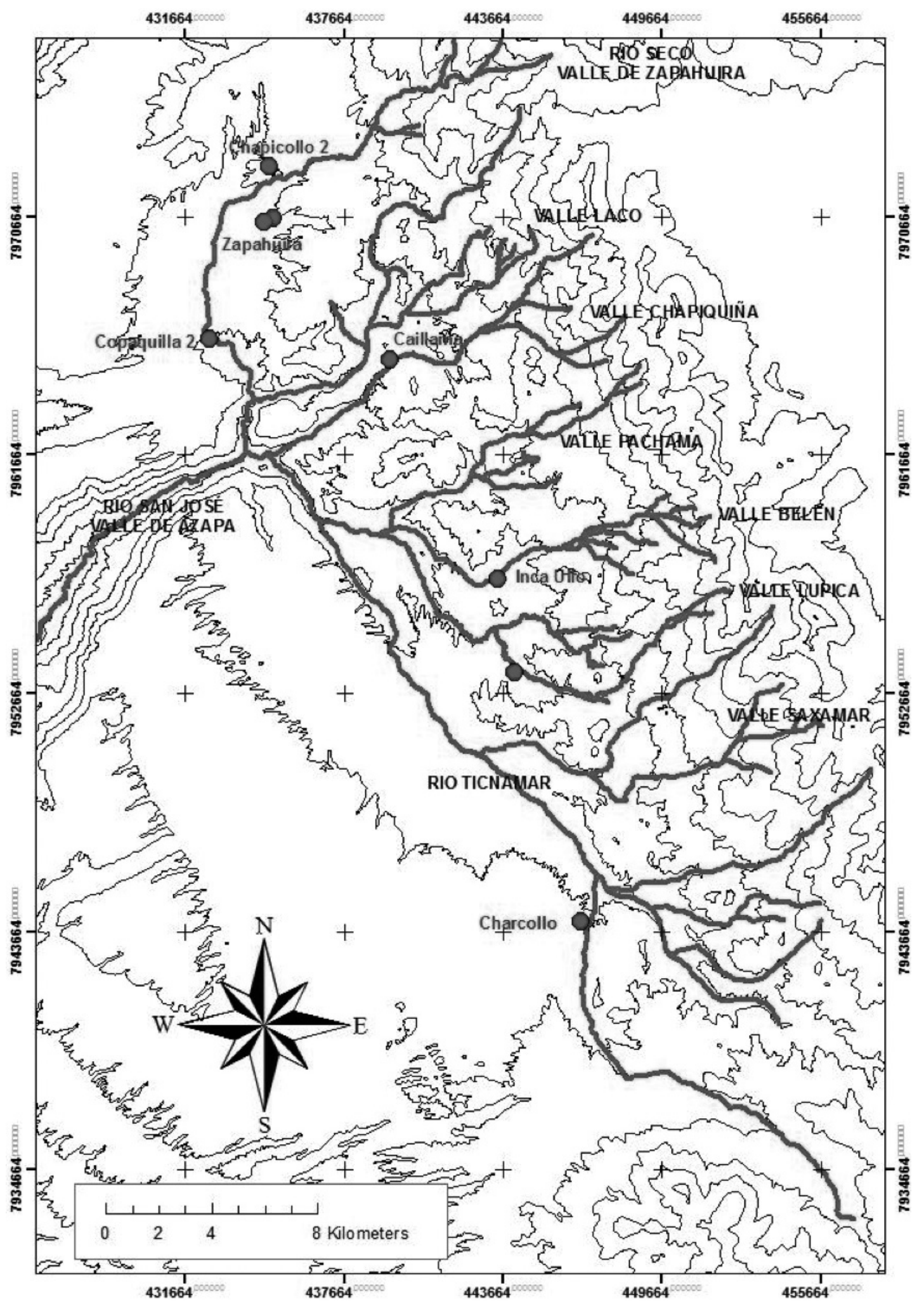

Figura 4. Precordillera de Arica, distribución de sitios con presencia de chullpas. 


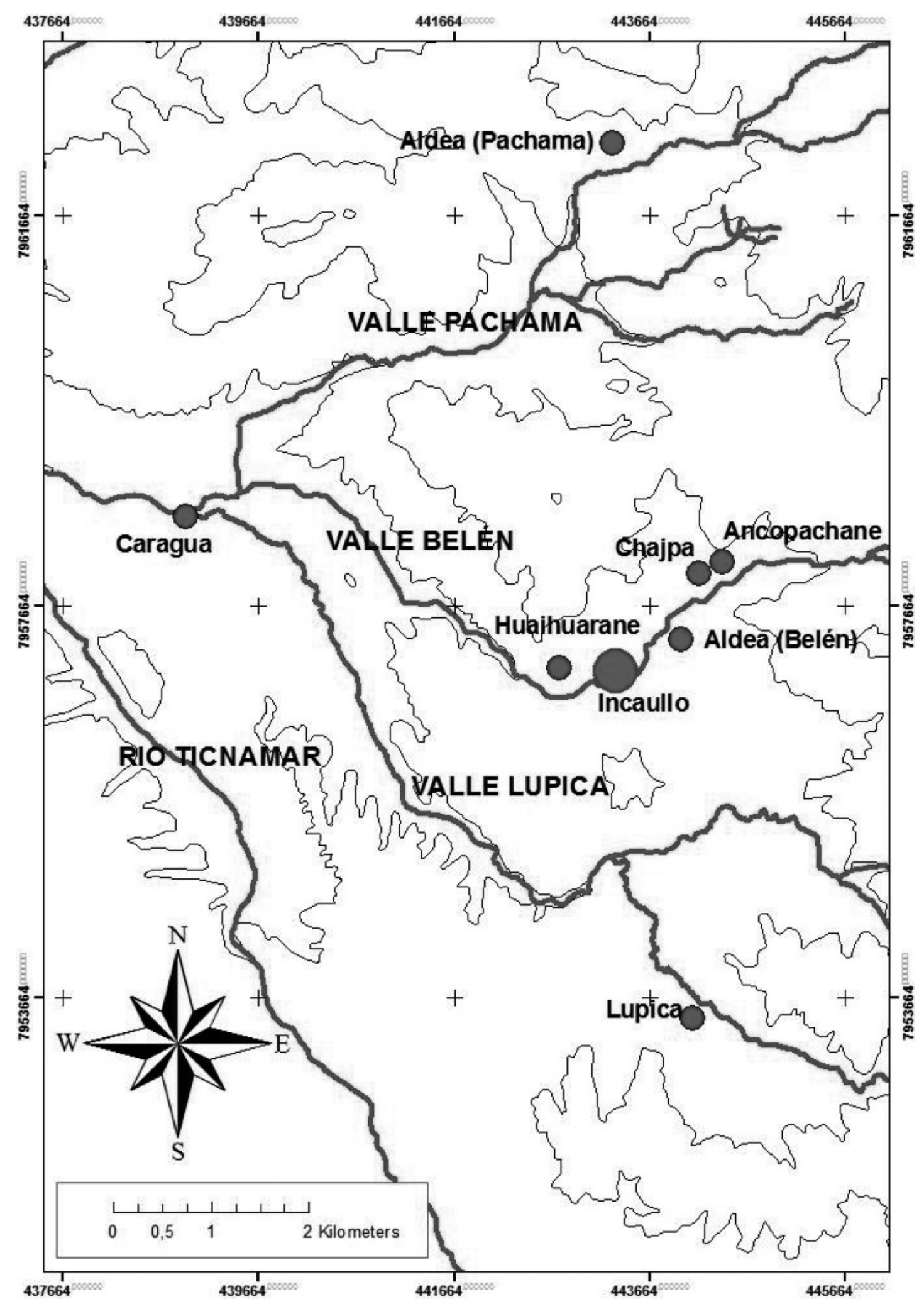

Figura 5. Sitios arqueológicos valle de Belén. 
posible que dicho recinto le haya dado el nombre al asentamiento: Inca, por la posibilidad de rememorar una época pasada y, ullo, por la función de corral que tiene quizás desde tiempos coloniales o al menos de la época Republicana.

Es entonces el recinto recién mencionado el que suscita nuestro interés en el presente trabajo. Como lo mencionáramos, este es un recinto de planta circular con paredes de doble hilada y unos $7 \mathrm{~m}$ de diámetro; posee actualmente un vano pequeño (posiblemente por su actual función de corral) de aproximadamente un metro de altura por $50 \mathrm{a} 60 \mathrm{~cm}$ de ancho. Hasta aquí el recinto no difiere mucho de la tradición de recintos de planta circular, característicos de la precordillera de Arica durante la prehistoria regional tardía. No obstante, el hecho de que este se encuentra en un sitio asociado a la presencia Inca en la zona (Dauelsberg, 1983), no se condice con el patrón rectangular que caracteriza las instalaciones Inca en nuestra región de estudio (cif. Muñoz y Chacama, 2006). Por otra parte, el recinto posee doce hornacinas $^{12}$ en su interior, de ellas dos corresponden más bien a vanos que comunican con el exterior ${ }^{13}$. Las hornacinas se sitúan a un promedio de $90 \mathrm{~cm}$ sobre el actual suelo del recinto, son de tamaño pequeño y muy bien delimitadas y enmarcadas por bloques de piedra (Figura 6).

Los dos elementos anteriores: un recinto circular asociado a presencia Inca y las doce hornacinas de su interior, apuntan hacia un especial tipo de recinto, el que a nuestro entender se vincula a funciones de tipo religiosa más que a funciones económicas, como lo sugería Dauelsberg (1983). En trabajos anteriores hemos hecho mención a templos incaicos que comparten el hecho de tener doce hornacinas y/o espacios divisorios en su interior, mencionando como ejemplo los templos de Sunturhuasi y Muyumarca; guardando las proporciones, se sugirió en ese entonces que este particular recinto del sitio Incaullo habría cumplido funciones de carácter ceremonial (Muñoz y Chacama, 2006:63).

\section{La casa de Tata Sabaya}

En la región de Sabaya se ha recogido un mito colonial que narra la historia de Martin Kapurata Condor Willca, héroe cultural de dicha región, hijo de Tata Sabaya y una joven virgen llamada Concebida. Condor Willka, a la muerte de su padre recibe a su vez la denominación Tata Sabaya. Al personaje en cuestión se le vincula con los momentos fundacionales de la región tanto de la época prehispana como colonial (Riviere, 1982:135 y ss, 2008:98,99). A este personaje mítico se le asocia también con la imagen de San Martín de Tours y se le representa alegóricamente bajo una iconografía ecuestre $^{14}$ (Gisbert, 1982).

El mito de Tata Sabaya genera también un paisaje mítico, constituido por el pueblo mismo de Sabaya, la montaña sagrada, las paradas y descansos que hizo el héroe en su recorrido y el entorno de este; para efecto de nuestra propuesta, y, en estrecha relación con este paisaje, nos interesa poner en relevancia lo que se conoce hoy como "la casa de Tata Sabaya". Dicho espacio ${ }^{15}$ constituye el escenario ritual de diversas ceremonias en torno a la montaña sagrada, particularmente aquella en la que se produce el cambio de alferazgo, y un nuevo alférez asume el rol de Tata Sabaya.

El espacio está en una pequeña explanada donde se encuentra un conjunto de estructuras de piedra que circundan un espacio abierto, dentro de las que destacan un pequeño templo católico con su respectiva posa ubicada en el espacio abierto; frente a su entrada, algunas estructuras de formas poco definidas, un par de recintos de planta rectangular con restos de hastiales y un gran recinto circular con muros de poco más de dos metros de altura. Junto a estas edificaciones, en el borde oeste del lugar se encuentra una chullpa de adobe bastante destruida, esta última construcción y restos de cerámica en su entorno indican que el asentamiento habría tenido una época de ocupación prehispana ${ }^{16}$ (Figura 7).

De las estructuras mencionadas con anterioridad, ¿cuál es la casa del Tata Sabaya?, ¿es todo el conjunto en sí o hay alguna estructura en particular?; de hecho, en la actualidad las ceremonias allí celebradas ocupan distintos espacios dentro del conjunto referido y aún se perciben restos de comidas ceremoniales en diferentes espacios; del mismo modo el lugar donde se encuentra la mesa y círculo de piedras que ocupan los principales de Sabaya se encuentra inmediatamente al este del pequeño templo cristiano. Para despejar nuestras interrogantes, G. Riviere, citando la versión transcrita del mito por el Cacique Licitador de Sabaya en 1974, nos señala que "Hoy en día [la casa del Tata Sabaya] está en ruinas pero nosotros la veneramos bajo el nombre de Paris Putuku (Riviere 1982:137) y en nota a pie de página aclara Putuku, nombre otorgado hoy a las casas redondas y cónicas, forma que también tiene la casa de Tata Sabaya. Paris, doble, parin, el término designa todo el espacio 


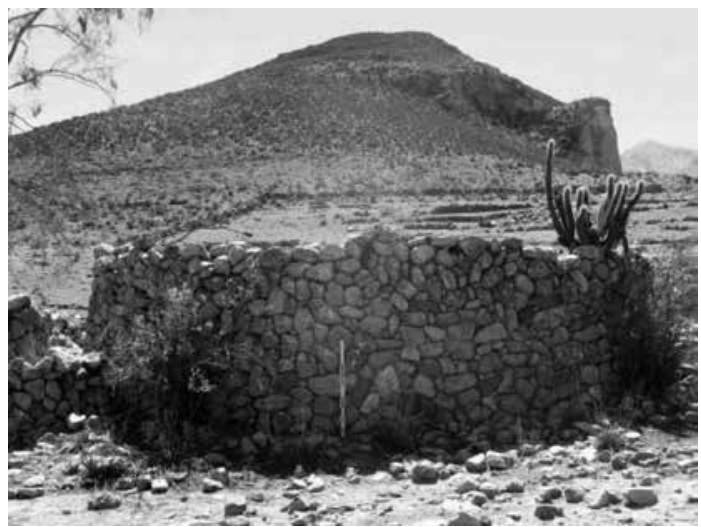

Foto 4. Recinto circular, Incaullo, vista sur.

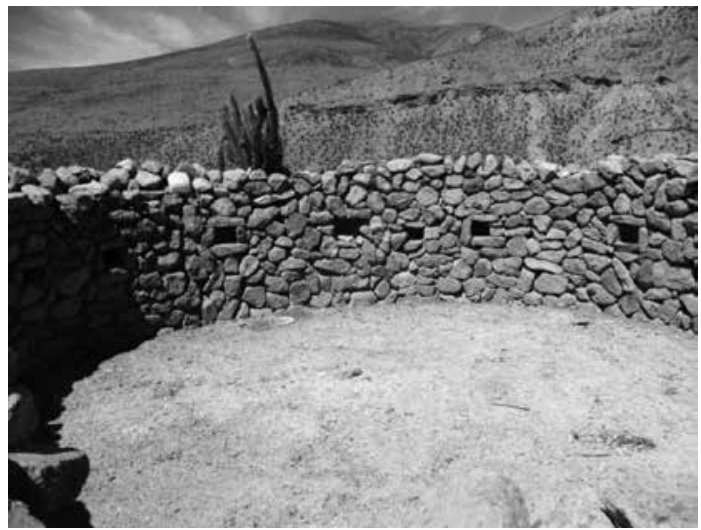

Foto 6. Recinto circular, Incaullo, vista interior, se aprecian 6 hornacinas.

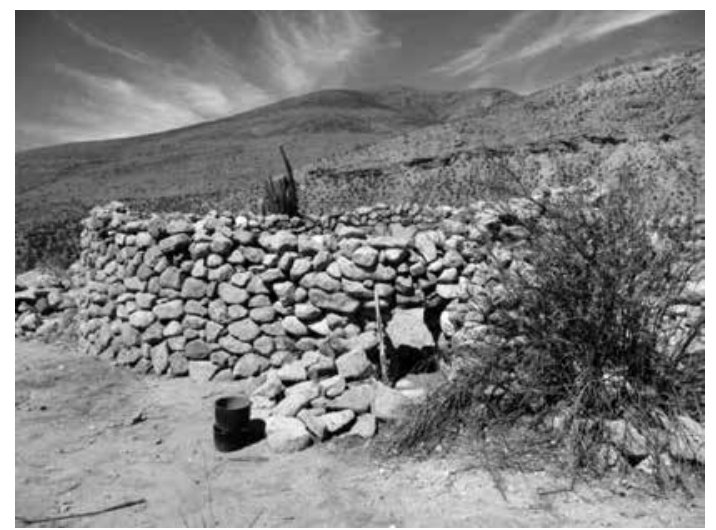

Foto 5. Recinto circular, Incaullo, vista norte, presenta vano actual.

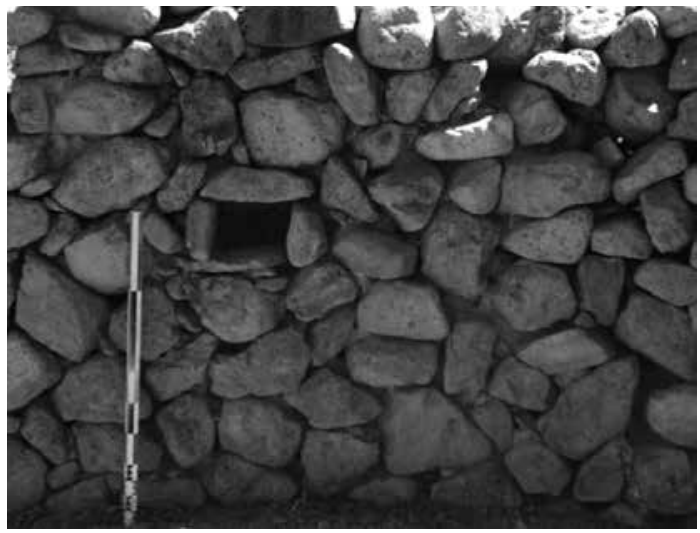

Foto 7. Recinto circular, Incaullo detalle hornacina.

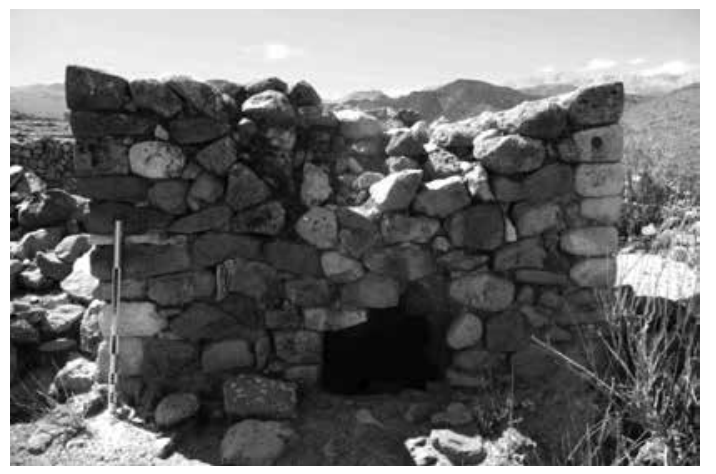

Foto 8. Chullpa aledaña al recinto circular.

Figura 6. Recintos circulares y Chullpa sector Incaullo, precordillera de Arica.

ritual que incluye las dos mitades de la comunidad (Riviere, 1982:137, nota 3).

Lo anterior señala claramente que la estructura circular mencionada anteriormente corresponde a la "casa de Tata Sabaya". Esta hoy se encuentra destruida en parte y reacondicionado su portal de ingreso con piedras canteadas. Igual que el recinto circular de Incaullo, habría tenido en su interior doce hornacinas ${ }^{17}$, de estas, por su actual estado de preservación, solo pudimos observar la existencia de 8 de ellas.

Las características señaladas tanto para la estructura de Incaullo como la de Kasinkira nos sitúan ante un par de edificios que, desde un punto de vista 


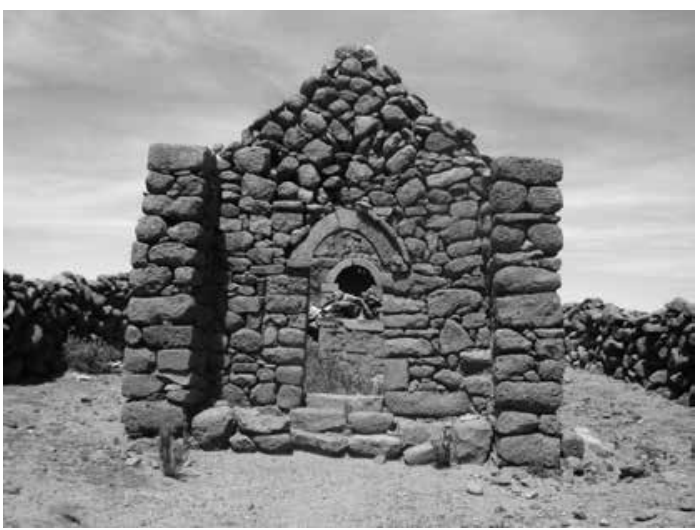

Foto 9. Capilla.

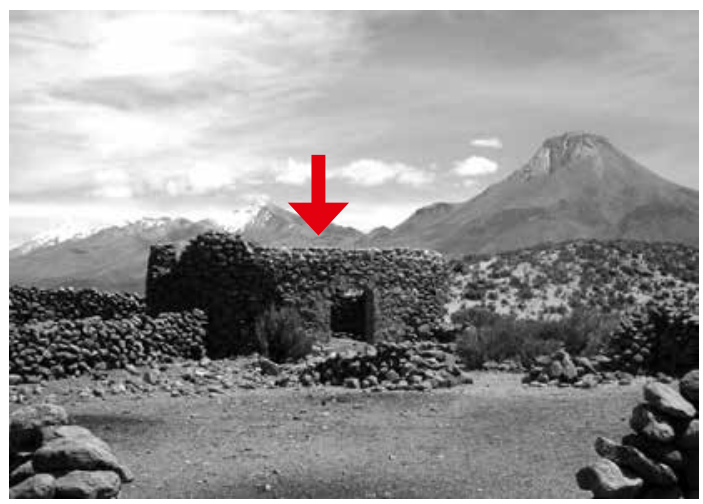

Foto 10. Casa de Tata Sabaya (señalada con flecha), al fondo, volcán Sabaya.

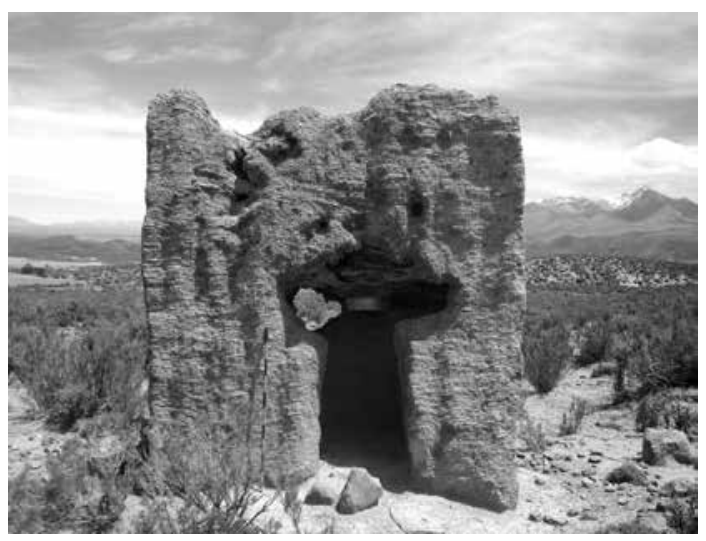

Foto 11. Chullpa al borde oeste del sitio.

Figura 7. Casa de Tata Sabaya.

formal, comparten un mismo concepto: tamaño, tipo de planta, vano de acceso y hornacinas internas; a esto se suma que ambos se encuentran acompañados de una torre funeraria o chullpa, además de otras edificaciones. Culturalmente, el primero de ellos se encuentra asociado a la presencia Inca en la precordillera de Arica y, el segundo, en la región de Sabaya, a un mito colonial que se remontaría a épocas prehispánicas. Como lo señalásemos en su momento, ambos recintos han sido asociados con espacios rituales, el primero con un "templo" incaico y el segundo como la casa del Tata Sabaya; el primero hoy se encuentra reutilizado como un corral y el segundo continúa su tradición como espacio ritual para la comunidad de Sabaya.

Las coincidencias formales de ambos recintos ¿son solo eso?: meras coincidencias, o tras estas hay concepciones ideológicas compartidas. No pretendemos responder estas interrogantes, conformándonos por ahora en presentar las evidencias que disponemos. Sí nos interesa remarcar el hecho de que la etnia Caranga, durante el siglo XVI y anteriormente, tuvo un amplio espacio de acción, el que incluía el territorio altiplánico de Sabaya y la vertiente occidental de la cordillera andina en los Altos de Arica. Conjuntamente con el manejo económico de ambos nichos ecológicos, sostuvo también un control político de ellos, y para el caso específico de las cabeceras de valles occidentales este control habría sido posible mediante el manejo simbólico de dicho espacio, incorporando su existencia en la memoria colectiva mediante la invocación de entidades tutelares, como lo vemos representado hoy en el Rodamiento Grande de los sabayeños; demandando un uso ancestral de los valles, evidenciado por edificios conmemorativos de carácter político y social como lo son las chullpas y quizás mediante la erección de cierto tipo de edificaciones cuya función se enmarca dentro del ámbito ideológico, específicamente el ritual.

\section{Agradecimientos}

El presente artículo es resultado del proyecto FONDECYT 1100132 "Historia de los pueblos andinos de Arica, Tarapacá y Atacama: las políticas estatales y eclesiásticas y las dinámicas de las comunidades indígenas, siglos XVI-XIX", coordinado por el Dr. Jorge Hidalgo L. Se agradece al proyecto de cooperación internacional Chile-Francia ECOS-CONICYT C06H04 "Dinámicas Culturales en el Sur Andino" que posibilitó el viaje del Dr. Gilles Riviere con el autor a la región de Sabaya, Bolivia; de igual forma se agradece al Dr. Riviere y al Sr. Eleuterio Alcons sus conocimientos y explicaciones de las manifestaciones rituales de Sabaya, señaladas en este trabajo. 


\section{Referencias citadas}

Aldunate, C.; J. Berenguer y V. Castro

1982 La función de las chullpas en Likán. Actas del VIII Congreso de Arqueología Chilena: 129-174. Sociedad Chilena de Arqueología, Universidad de Chile. Valdivia.

Cereceda, V.

1993 Cette étendue entre l'altiplano et la mer... Un mythe chipaya hors texte". En: Mémoire de la Tradition: 227-284. Editado por: Aurore Becquelin et Antoinette Molinié. Institut d'Ethnologie, Universidad de Nanterre. Paris.

Cereceda, V.

2010 Una extensión entre el altiplano y el mar. Relatos míticos Chipaya y el norte de Chile. Estudios Atacameños 40: 101-130.

Chacama, J.

2009a Chullpas, los sepulcros abiertos de la precordillera de Arica. Nuevas aproximaciones a un viejo tema. En: Informe Final proyecto UTA 3749. Universidad de Tarapacá.

Chacama, J.

2009b Tecnología andina análisis constructivo de chullpas en la precordillera de Arica, norte de Chile. En: Informe Final proyecto UTA 3749. Universidad de Tarapacá.

Chacama, J.

2010 El proceso ocupacional de la precordilllera de Arica a la luz del modelo de verticalidad. Norte de Chile siglos X al XV. Manuscrito en poder del autor.

Dauelsberg, P.

1983 Investigaciones arqueológicas en la sierra de Arica, sector Belén. Chungara 11:63-83.

Doyle, M.E.

1988 The Ancestros Cult and Burial Ritual in Sevententennth and Eightenn Century Central Peru. Dissertation for the degree Doctor of Philosophy. Universidad de California. Los Angeles.

Duchesne, F.

2005 Tumbas de Coporaque. Aproximaciones a concepciones funerarias Collaguas. Boletín del Instituto Francés de Estudios Andinos 34(3): 411-429.

Duchesne, F. y J. Chacama

2012 Torres funerarias prehispánicas de los Andes CentroSur: muerte, ocupación del espacio y organización social. Estudio comparativo: Coporaque, Cañón del Colca (Perú), Chapiquiña, precordillera de Arica (Chile). Chungara, Revista de Antropología Chilena 44 (4): 605-619.

Durston, A y J. Hidalgo

1999 La presencia andina en los valles de Arica, siglos XVIXVIII: casos de regeneración colonial de estructuras archipielágicas. Chungara 29 (2): 210-249, Universidad de Tarapacá.

Hidalgo, Jorge

1997 Los Yungas de Tarata en el siglo XVIII. En Antropología y Arqueología e Historia. Homenaje a María Rostworoski: 425-442. Editado por R. Varón y J. Flores. Instituto de Estudios Peruano.

Hidalgo, J.

1999 Relaciones protohistóricas interétnicas entre las poblaciones locales y altiplánicas en Arica. En: La Integración Sur Andina Cinco Siglos Después: 161-173. Editado por X. Albó et al. Centro de Estudios Regionales Bartolomé Las Casas.
Hidalgo J. y G. Focacci,

1986 Multietnicidad en Arica, Siglo XVI. Evidencias Etnohistóricas y Arqueológicas. Chungara 16-17:137-147.

Hidalgo J, M. Marcilli y P. Arévalo

1991 Complementariedad andina y la expansión de las haciendas en el valle de Lluta y la sierra de Arica: 1730-1838. Actas del XI Congreso Nacional de Arqueología Chilena. Tomo II: 31-41. Santiago.

Isbell, W.

1996 Mummies and mortuary monuments. A Postprocesual Prehistory of Central Andean Social Organization. Austin: University of Texas Press.

Muñoz, I. y J. Chacama

2006 Complejidad Social en los Altos de Arica Territorio Etnicidad y Vinculación con el Estado Inca. Ediciones Universidad de Tarapacá. Santiago.

Kesseli, R.; M. Pärssinen

2005 Identidad étnica y muerte: torres funerarias (chullpas) como símbolos de poder étnico en el altiplano boliviano de Pakasa (1250-1600 d. C.) Boletín del Instituto Francés de Estudios Andinos 34(3): 379-410.

Platt. T.

1988 Pensamiento político Aymara. Raíces de América. En: El Mundo Aymara: 365-450. Compilado por Xavier Albó. UNESCO, Sociedad Quinto Centenario. Alianza Editorial. Madrid.

Platt, T., T. Bouysse-Cassagne y O. Harris, con el aliento de Thierry Saignes.

2006 Qaraqara-Charka. Mallku, Inka y Rey en la provincia de Charcas (siglos XV-XVII). Historia de una Confederación Aymara. Edición documental y ensayos interpretativos. La Paz: Instituto Francés de Estudios Andinos, Plural Editores, University of St. Andrews, Univeristy of London, Inter American Foundation, Fundación Cultural del Banco Central.

Riviere, G.

1979 Intercambio y Reciprocidad en Caranga. Antropología 1 (1): 85-113. Revista del Instituto Nacional de Antropología. La Paz.

Riviere, G.

1982 Sabaya: Strucures Socio-Ecomonique et Réprésentations Symboliques dans Les Caranga. Bolivie. Tesis doctoral de etnología $3^{\circ}$ ciclo. Paris: Ecole de Hautes Etudes en Sciences Sociales.

Riviere, G.

2008 Amtat Jan Amtata... Caciques et Mallku dans les communautés Aymara du Caranga (Bolivie). En Pour une Histoire Souterraine des Ameriques. Jeux de Memories Enjeux d'Identités: 71-99. Recherches Amerques Latines-L' H rmattan.

Romero, A.

2005 Organización Social, Económica y Política de la Prehistoria Tardía de los Valles de Arica. Memoria para optar al título de Arqueólogo. Universidad de Chile.

Salomon, F.

1995 "The Beatiful Grandparents": Andean Ancestors Schirines and Mortuary Ritual as Seen Through Colonial Records. En: Tombs for the Living: Andean Mortuory Practice. Editado por T. Dillehay. Dumbarton Oaks. Washington D.C. 
Notas

1 Ver también Platt et al. 2006.

2 La localidad de Sabaya en territorio boliviano se encuentra a escasos $50 \mathrm{~km}$ de la localidad de Isluga en territorio chileno.

3 Los kilómetros son tomados en línea recta desde Sabaya al hito en referencia.

4 Información proporcionada por Eleuterio Alcons, exalférez mayor de Sabaya (23 de marzo de 2009). Para el mismo tema ver Riviere 2008:87.

5 Cumbres que conforman el Rodamiento Grande, información proporcionada por Eleuterio Alcons, exalférez mayor de Sabaya (23 de marzo de 2009). No nos fue posible ubicar todos los hitos mencionados en los mapas a nuestra disposición.

6 Si bien Chungara es el nombre de un lago, pensamos que el rodamiento hace referencia al par de volcanes conocidos como Payachatas (Parinacota y Pomerape), los que se encuentran en las orillas del mencionado lago.

7 Palabras utilizadas para cerrar el ruedo.

8 Estos mecanismos de memorias reflejados en hitos geográficos no son exclusivos de esta comunidad; Verónica Cereceda en un artículo sobre relatos Chipaya proporciona la visión de un territorio ancestral cuyo recuerdo subyace de manera "inconsciente" en un conjunto de relatos míticos manejados actualmente por los Chipaya. Dichos relatos configuran paisaje, rutas, y personajes andinos y de la religiosidad católica (Cereceda, 1993, 2010).

9 Para el mismo tema ver Riviere 2008:87.

10 Posterior a dicha publicación, nuevas investigaciones realizadas especialmente en el altiplano de Bolivia incrementan el conocimiento sobre este tema. Mención especial recae en el número 2 (5-6) de la revista Pumapunku (1993), dedicada completamente al tema. En dicho número, junto a nuevas investigaciones, especialmente para el altiplano boliviano, destaca la traducción y reproducción de antiguos trabajos poco conocidos hasta hoy; entre estos el de H. Trimborn de mediados del siglo pasado sobre el conjunto de chullpas de Sica Sica y las notas de J. Sever de comienzos de siglo sobre las chullpas de Pukara. Este conjunto de artículos, sumados a los recientes trabajos de T. Gisbert sobre las chullpas del río Lauca (Gisbert et al. 1996, Gisbert 2001), F. Gill (2001a, 2001b), F. Duchesne (2005), R. Kesseli y M. Parsinen (2005), J. Chacama (2010), F. Duchesne y J. Chacama (2012) entre otros, han contribuido a complementar el conocimiento en torno a este fenómeno.
11 Es necesario señalar que desde el punto de vista de la investigación arqueológica, el espacio precordillerano habría sido poblado inicialmente por poblaciones yungas de valles occidentales (ca. 1100 d.C.) y posteriormente por las poblaciones altiplánicas (ca. 1200 d.C). Suponemos que en el intertanto, antes y coincidente con la presencia Inca en la zona del Collao, se gestó un proceso político que permitió que las poblaciones altiplánicas lograran una posición jerárquica respecto de las poblaciones yungas (cif. Chacama, 2010). En dicho proceso se habrían generado mecanismos de memoria, ellos daban cuenta de antiguos fundadores de linaje, cuya presencia estaba manifiesta en los sepulcros abiertos de la precordillera.

12 Por medio de la documentación colonial sabemos que las hornacinas fueron utilizadas para depositar ofrendas o poner imágenes sacras.

13 Percy Dauelsberg, quien tuvo la ocasión, en la década del 60 , de observar el recinto de las hornacinas en un mejor estado de conservación, señala lo siguiente: "La construcción es de forma circular, tiene $12 \mathrm{~m}$ de diámetro con un muro de 2,5 $\mathrm{m}$ de altura, pudiéndose observar doce hornacinas en su interior de 25 por $40 \mathrm{~cm}$ y dos ranuras verticales que pudieron haber servido para la ventilación del recinto más que para ventanas. Hoy estos recintos circulares se han cerrado totalmente, dejando una pequeña abertura para que pueda entrar y salir el ganado ovino que pernocta en estos recintos" (Dauelsberg, 1983:73).

14 La localidad de Codpa, en territorio chileno (1.870 msnm, 421504.44 E 7917410.45 S), tiene como patrono a san Martín de Tours. En una de sus representaciones destaca un lienzo que tiene la misma representación iconográfica utilizada en el altiplano sabayeño. La localidad de Codpa se encuentra prácticamente en la misma latitud que la localidad de Sabaya, un camino tropero existente quizás desde épocas prehispanas une ambas localidades por el paso del río Lauca.

15 La casa de tata Sabaya se encuentra en la ladera sur del cerro Kasinkira, frente al cerro de Tata Sabaya y a unos $20 \mathrm{~km}$ a vuelo de pájaro de la localidad de Sabaya.

16 Visita al cerro Kasinquira, en marzo de 2009, guiada por don Eleuterio Alcons, exalférez de Sabaya, en compañía del Dr. Gilles Riviere y los entonces estudiantes de Posgrado en Antropología, UTA: Francisca Urrutia y de pregrado en Arqueología, UBI: Mauricio Navarro.

17 Comunicación personal G. Riviere (marzo de 2009). 
